\title{
THE HISTOMORPHOLOGICAL STUDY OF COLORECTAL POLYPS WITH EMPHASIS TO THEIR PROLIFERATIVE ACTIVITY
}

\author{
Nisha Gopalan', Laila Raji Navamoni², Sankar Sundaram³
}

${ }_{1}^{1}$ Resident, Department of Pathology, Government Medical College, Kottayam.

2Professor, Department of Pathology, Government Medical College, Kottayam.

3Professor and HOD, Department of Pathology, Government Medical College, Kottayam.

ABSTRACT

\section{BACKGROUND}

Colorectal cancer is the second leading cause of cancer deaths worldwide. Most colorectal cancers are believed to arise from benign adenomatous polyps. The risk determination of adenomatous polyps for changing into adenocarcinoma is very important. This study was conducted to assess the various morphological patterns of colorectal polyps and to determine the degree of dysplasia in adenomatous polyps.

The objectives of the present study were to determine the location and various histopathological types of colorectal polyps, to assess the degree of dysplasia in adenomatous polyps and to assess the proliferative activity by Ki-67 in various polyps and its relation to grade of dysplasia.

\section{MATERIALS AND METHODS}

A descriptive study was conducted on 65 cases of endoscopically and surgically removed colorectal polyps from patients admitted to gastroenterology and surgery departments, received in the Department of Pathology, Government Medical College, Kottayam during a period of 18 months. Statistical analysis was done with SPSS software.

\section{RESULTS}

Among the 65 cases, 46 patients were males and 19 cases were females. The male-to-female ratio was 2: 1. Majority of patients had complaints of bleeding per rectum. The maximum number of patients were in the age group between 50 to 60 yrs. 41 cases were adenomatous polyps and tubular adenomas were the predominant subtype of adenomatous polyps. Majority of polyps were present on left side of colon. Left-sided polyps show more high-grade dysplasia than right-sided polyps. Polyps with villous architecture have high-grade dysplasia than those of tubular architecture. Pedunculated polyps have more high-grade dysplasia than sessile polyps. No association was found between size of polyp and degree of dysplasia. There was also no association between age of patient and degree of dysplasia. Significant correlation was found between the grade of dysplasia and Ki-67 expression.

\section{CONCLUSION}

Left-sided polyps with villous architecture have more high-grade dysplasia. There was significant correlation between Ki-67 and degree of dysplasia in adenomatous polyps.

\section{KEYWORDS}

Adenomatous Polyps, Ki-67, Dysplasia.

HOW TO CITE THIS ARTICLE: Gopalan N, Navamoni LR, Sundaram S. The histomorphological study of colorectal polyps with emphasis to their proliferative activity. J. Evolution Med. Dent. Sci. 2017;6(93):6708-6711, DOI: 10.14260/jemds/2017/1452

\section{BACKGROUND}

Colorectal cancer accounts for about $10 \%$ of all cancers. There are several types of colon polyps. They include nonneoplastic polyps and neoplastic polyps. Non-neoplastic polyps- These polyps are not likely to develop into cancer. Hyperplastic polyps, hamartomas and inflammatory polyps are all non-neoplastic polyps. Neoplastic polyps are those polyps that are more likely to develop into cancer. Adenomas are the most common type of neoplastic polyps. They are classified as tubular, tubulovillous or villous adenomas depending on the presence and volume of villous tissue. ${ }^{1}$

'Financial or Other Competing Interest': None.

Submission 12-10-2017, Peer Review 21-11-2017,

Acceptance 27-11-2017, Published 11-12-2017.

Corresponding Author:

Dr. Laila Raji Navamoni,

Professor,

Department of Pathology,

Government Medical College, Kottayam.

E-mail: lailarajin@gmail.com

DOI: $10.14260 /$ jemds/2017/1452

\section{(c) (i) $(5)$}

Tubular has $0 \%$ - $25 \%$ villous tissue, tubulovillous has $25 \%$ $75 \%$ of villous tissue and villous adenomas has $75 \%-100 \%$ of villous tissue. ${ }^{2}$ Tubular adenomas are composed of straight or branched tubules of dysplastic tissue. This is the most common histological subtype constituting approximately $65 \%-80 \%$ of all polyps removed. The size varies from less than $0.1 \mathrm{~cm}$ to several centimetres in diameter, but most are a little less than $1 \mathrm{~cm}$. Small adenomas are sessile, but lesions approaching $1 \mathrm{~cm}$ in diameter are usually pedunculated. Villous adenomas have long, finger-like projections. Only $5 \%$ - $10 \%$ of neoplastic polyps are villous adenomas. Compared with tubular adenomas, villous adenomas are more commonly sessile and are more likely to have severe atypia or dysplasia. Tubulovillous adenomas have elements of both the above cellular patterns. Approximately, $10 \%-25 \%$ of polyps are tubulovillous. In adenomas showing mild dysplasia- nuclei are slightly enlarged, show crowding and elongation. Mucin secretion is reduced, but still evident and polarity is retained. In adenomas showing moderate dysplasia there is focal loss of nuclear polarity, an increase in the nucleocytoplasmic ratio and further loss of mucin 
production. The nuclei are still slender with finely stippled chromatin and cytological features fall short of malignancy. In adenomas showing severe dysplasia- the nuclei are ovoid, vesicular and contain prominent nucleoli, the cytological appearances resemble those of malignant epithelium (carcinoma-in-situ). There is no mucin secretion. The risk of malignant change is increased in patients with multiple adenomas, in villous lesions, in larger sized lesions and in adenomas showing high-grade or severe dysplasia.,4 The factors contributing to the development of colonic adenomas are multiple; however, it is well accepted that both genetic susceptibility and environmental factors play a role in this process. Smoking is shown to be a risk factor for the development of colonic polyps. ${ }^{5}$ Polyps can be sessile or pedunculated. A sessile polyp grows directly from the stem without a stalk. As sessile polyps enlarge, proliferation of cells adjacent to the mass and the effects of traction on the luminal protrusion may combine to produce a stalk. These polyps with stalk are termed pedunculated polyps. Polyps may cause gross rectal bleeding or rarely symptoms of partial bowel obstruction. Most polyps are asymptomatic lesions, which are detected by screening or diagnostic studies performed for other purposes. Colorectal polyps are very common in Western countries. They are found in 30\% of autopsies performed in people aged 60 yrs. or above. The importance of polyps is their well-recognised relationship to colorectal cancer. ${ }^{6}$ It is generally accepted that 95\% colorectal cancers arise from benign, neoplastic adenomatous polyps (adenomas). Colorectal neoplasia progresses through a continuous process from normal mucosa, to benign adenoma, to carcinoma. The concept regarding adenomacarcinoma sequence is the main reason for preventing, screening and removal of adenomatous polyp using colonoscopy. The factors that have been repeatedly shown to be independent risk factors for malignancy include the size of polyp and its grade of dysplasia. So the aim of this study is to assess the various morphological patterns of colorectal polyps and to determine the degree of dysplasia in adenomatous polyps.

Increased or altered proliferation is believed to be an early event in adenoma-carcinoma sequence in colon. Ki-67 protein is an immunohistochemical marker utilised for identification of proliferative cells. It is a proliferationassociated nuclear antigen expressed in all cycling cells except resting cells in the G0 phase, and it reflects cells in the G1, S, G2 and M phases in particular. ${ }^{7,8}$ The Ki- 67 gene is present on the long arm of the human chromosome 10 (10q25). The half-life of Ki-67 protein has been estimated approximately 60 - 90 minutes. The Ki-67 protein is phosphorylated via serine and threonine with a critical role in cell division. This has been observed from the arrest of cell proliferation when Ki-67 is blocked either by microinjection of blocking antibodies or by inhibition of dephosphorylation. The Ki-67 expression is estimated as the percentage of the tumour cells positively stained by the antibody with nuclear staining being most common criterion of positivity. MIB- 1 is a monoclonal antibody and it recognises the Ki-67 nuclear antigen in the formalin fixed paraffin embedded tissue sections, and its reactivity is not affected if there is a delay in fixation. Thus, the presence of Ki-67 antigen is strictly associated with cell cycle suggesting an important role of this structure in the maintenance and regulation of cell cycle.
This study was conducted to assess the proliferative activity of adenomatous polyps using Ki-67.

\section{MATERIALS AND METHODS \\ Type of Study}

Descriptive study.

\section{Study Period}

18 months (July 2015 to December 2016).

\section{Study Setting}

Department of Pathology, Govt. Medical College, Kottayam.

\section{Sample Size}

65 (Sample size, $N=\left(Z(1-\propto / 2)^{\wedge} 2 \mathrm{Pq}\right) / \mathrm{d}^{\wedge} 2, \mathrm{p}=$ prevalence/ proportion in previous study, $q=100-p, d=$ precision/ allowable error- $20 \%$ ).

\section{Inclusion Criteria}

All colorectal polypectomy specimens received in the Pathology Department with adequate material.

\section{Exclusion Criteria}

All colorectal polyps with inadequate data and biopsy material.

\section{Study Procedure}

65 cases of endoscopically and surgically removed colorectal polyps received in the Department of Pathology from patients admitted to Gastroenterology and Surgery Departments in Government Medical College, Kottayam, is included in this study. Biopsies received in the Department of Pathology were fixed in $10 \%$ neutral buffered formalin, appropriate bits of entire polyps including stalk was taken, processed, paraffin embedded, sectioned, stained by routine haematoxylin and eosin and studied microscopically. Clinical details were obtained as per clinical proforma. Parameters analysed were age, gender, presenting complaints, endoscopic findings, gross, histological type of polyp and degree of dysplasia. Degree of dysplasia was divided into low and high grades, based on whether the dysplastic features are limited to half of epithelium or above it. Appropriate blocks were selected and sections of 4 micron thickness were taken into slides. Antigen retrieval was done by the heat induced epitope retrieval method and immunohistochemical staining using MIB-1 antibody was done. Nuclear positivity was counted among 500 cells and percentage of positive cells was recorded. More than $10 \%$ positivity is taken as high Ki-67 index.

\section{Data Management and Analysis}

The data will be entered in Microsoft Excel and further statistical analysis will be done using SPSS software version 16.

\section{RESULTS}

Among the 65 cases, $71 \%$ patients were males and $29 \%$ cases were females and the male-to-female ratio was $2: 1$. The maximum number of patients were in the age group between 50 to 60 yrs. Majority of patients had complaints of bleeding per rectum. Tubular adenomas were the predominant subtype of adenomatous polyps and majority of polyps were found on left side of colon. Left-sided polyps show more high- 
grade dysplasia than right-sided polyps and polyps with villous architecture have high-grade dysplasia than those of tubular architecture. Pedunculated polyps showed highgrade dysplasia and sessile polyps have low-grade dysplasia. There was no association between the size of polyp and degree of dysplasia. Also, no association was found between age of patient and degree of dysplasia. There is a significant correlation between the grade of dysplasia and Ki-67 expression.
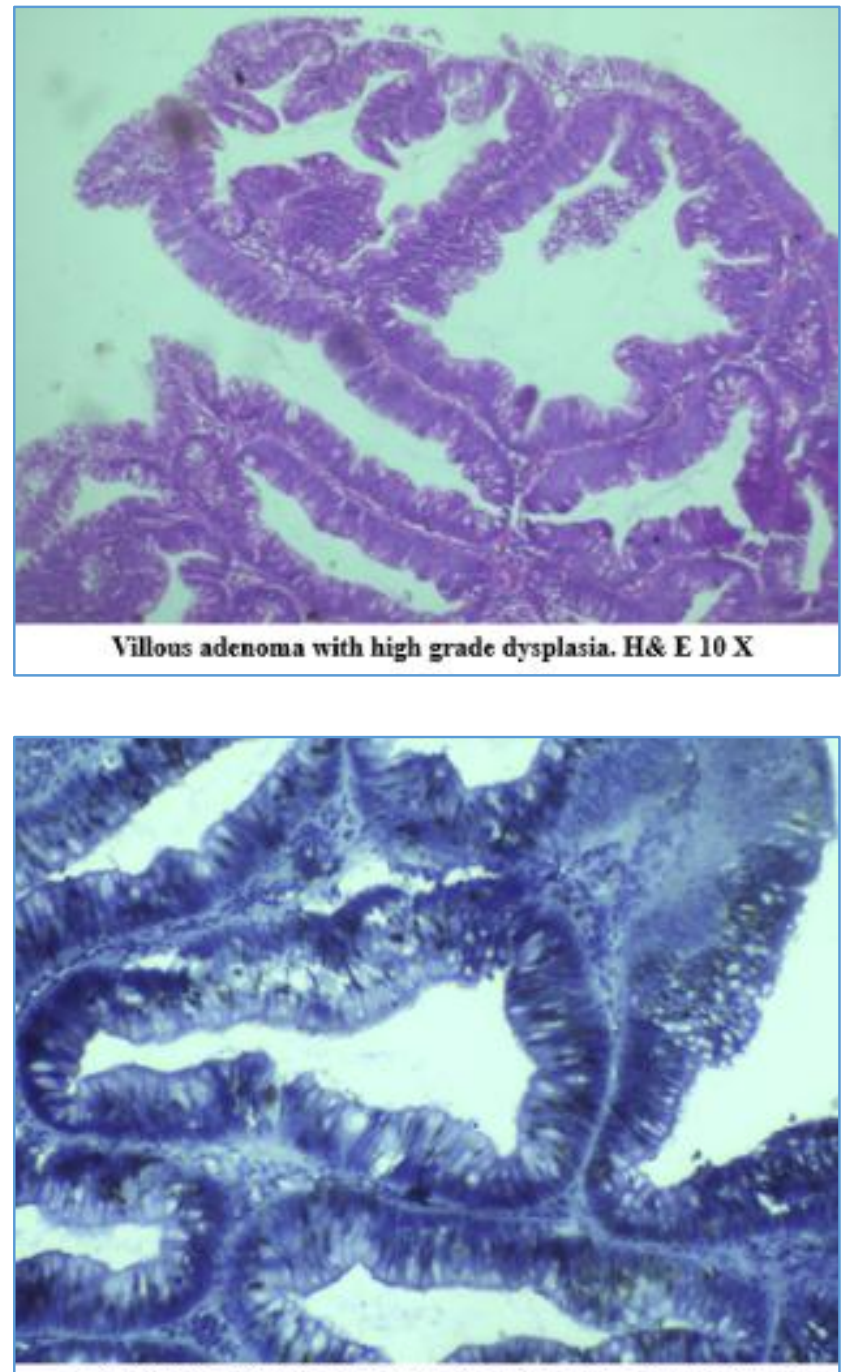

IHC $\mathrm{Ki}-67$ on villous adenoma with high grade dysplasia.40X

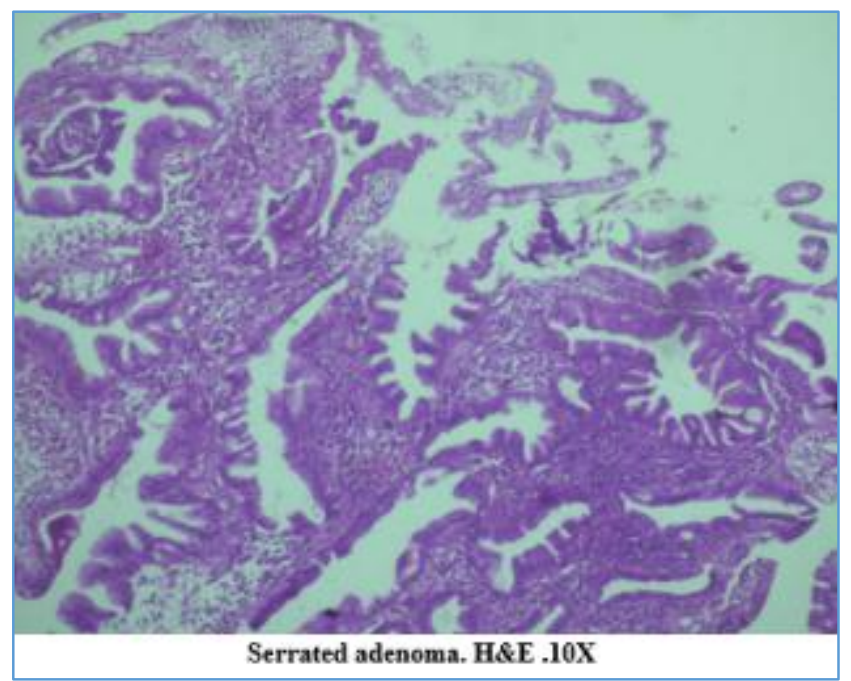

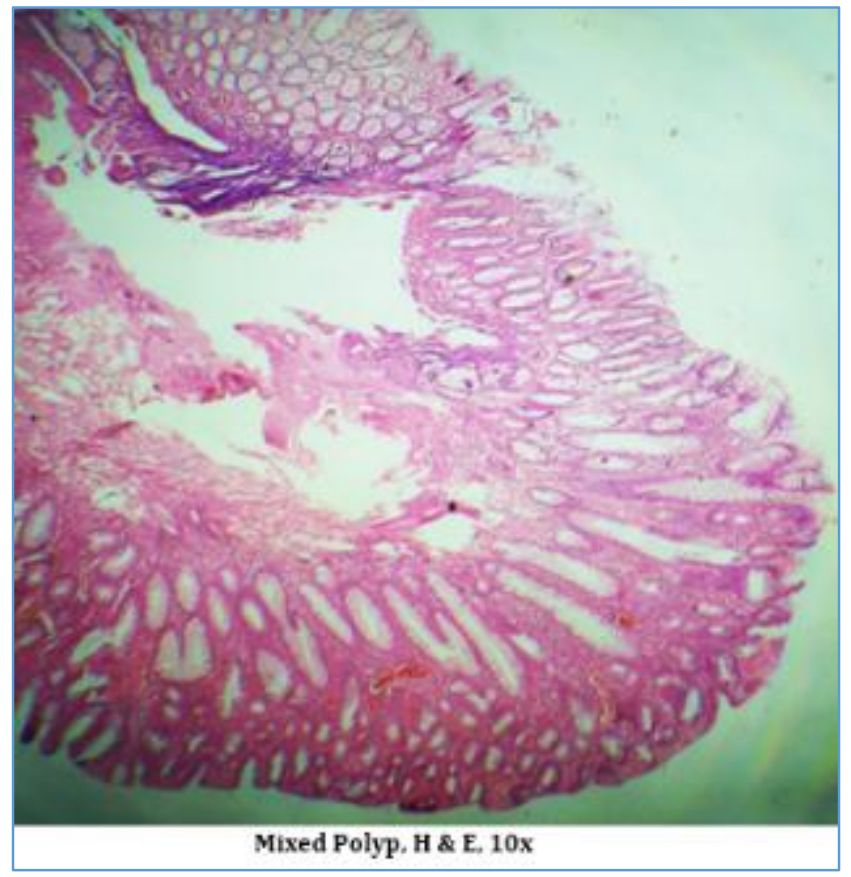

\section{DISCUSSION}

The present study was conducted on 65 endoscopically and surgically removed polyps received in the Department of Pathology from patients admitted to Gastroenterology and Surgery Departments in Government Medical College, Kottayam, during the study period between July 2015 and December 2016 (18 months).

Among the 65 cases studied, majority of patients (71\%) were males and $29 \%$ were females. In the previous studies in India by Jose Tony and K Harish in 2005 also showed male predominance. They have the opinion that smoking and alcohol consumption in males are associated with increased risk of colorectal polyposis.

In the present study, the maximum numbers of patients fall under the age groups of 50 to 60 years. It seems to affect people around 50 years of age. This result was concordant with the study by Jose Tony et al. In this study, majority of polyps (77\%) were seen on left side of colon.

In the current study, majority of patients (73\%) had bleeding per rectum. This is in accordance with the study conducted by Thomas et al 2005, who found that most common indication for colonoscopy was haematochezia in $40 \%$ followed by altered bowel habits in 35\%, lower abdominal pain in $15 \%$ and evaluation for anaemia in $10 \%$ patients. This may be because people with bleeding per rectum search medical help earlier than other symptoms.

Among the adenomatous polyps 29 cases were tubular adenomas, 12 cases were tubulovillous adenomas and 6 cases were villous adenomas. So, majority of polyps were tubular adenomas. This is because tubular adenomas are the predominant type of polyps among the adenomatous polyps, whereas villous is least. Out of 65 cases studied, polyps with villous architecture showed high-grade dysplasia than those with tubular architecture. This is in accordance with a study conducted by Khatibzadeh et al, in Tehran, 2004 who concluded that villous component have 16 -fold risk of highgrade dysplasia.

In this study two cases of adenocarcinoma were seen to arise from tubulovillous polyp with high-grade dysplasia. 
In the present study, left-sided polyps have more potential for high-grade dysplasia than right-sided polyps. Similar result was obtained in a study conducted by Khatibzadeh and Ziaee in Iran, 2004. This may be because villous polyps which have more malignant potential are situated more in rectum and rectosigmoid.

From the various studies, the size of polyp has been reported as an independent predictor of malignancy in colorectal carcinoma. The risk of developing adenocarcinoma is $1 \%$ in adenomas upto $1 \mathrm{~cm}$ in size, $10 \%$ in adenomas from $1 \mathrm{~cm}$ to $2 \mathrm{~cm}$ in diameter and $50 \%$ in those greater than $2 \mathrm{~cm}$ in diameter. But according to our results, no association was found between degree of dysplasia and size of polyps. This may be because number of polyps with larger size was less.

In the present study, sessile polyps had lower grade dysplasia. This is contrary to study conducted by Jose Tony, 9 in which high-grade dysplasia was seen in $47 \%$ of sessile polyps and $6 \%$ of pedunculated polyps. Sessile polyp has increased chance of high-grade dysplasia and malignancy, because the pathway of invasion of neoplastic cells from the surface of polyp into the submucosal layer is short.

It is known that age is an independent risk factor for highgrade dysplasia and malignancy. But in the present study, there was no association between age and degree of dysplasia. This may be because small number of people was included in higher age group.

In this study, Ki-67 was more expressed in polyps with high-grade dysplasia. This was concordant with the study by Faris Lufti et al, 2011. Ki-67 positive cells showed uniform brown stained nuclei. In low-grade dysplasia, positive cells were seen upto half of epithelium, whereas in high-grade dysplasia positive cells were seen in two-thirds to full thickness of epithelium.

\section{CONCLUSION}

In this study conducted in 65 colorectal polyps in the Department of Pathology, Government Medical College, Kottayam, the following conclusions were made-

1. Majority of colorectal polyps were found on left side of colon. Among the 65 colorectal polyps, 50 cases were adenomatous polyps and tubular adenomas constitute the predominant type of adenomatous polyp.

2. The degree of dysplasia in adenomatous polyp is assessed by looking into the features like increase in number of glands and cells per unit area compared to normal mucosa, nuclear hyperchromasia, elongation and stratification. The cells also have increased number of mitosis and decreased mucin production. In low-grade dysplasia, these features are limited to the lower half of epithelium, whereas in high-grade dysplasia these features are seen in two-thirds to full thickness of epithelium. In this study, those polyps with left-sided location and villous architecture have high-grade dysplasia. The size of polyp and age of the patient showed no association with the degree of dysplasia.
3. In this study, immunohistochemical marker Ki-67 was utilised for the identification of proliferative cells. A diffuse brown nuclear stain shows a positive expression for Ki-67. In low-grade dysplasia, positive cells were seen upto half of the epithelium, whereas in high-grade dysplasia positive cells were seen in two-thirds to full thickness of epithelium. It was found that there is significant correlation between Ki-67 and degree of dysplasia in adenomatous polyps.

Those polyps with high Ki-67 expression are more liable to transfer to malignancy.

\section{ACKNOWLEDGEMENTS}

I express my heartfelt thanks and gratitude to Dr. Sankar S, Head of the Department, Department of Pathology, Government Medical College, Kottayam and my guide Dr. Laila Raji, Professor, Department of Pathology, Government Medical College, Kottayam for their passion, dedication and help.

\section{REFERENCES}

[1] Groff DB, Nagaraj HS. Rectal prolapse in infants and children. Am J Surg 1990;160(5):531-2.

[2] Broughton T, Sington J, Beales IL. Statin use is associated with a reduced incidence of colorectal adenomatous polyps. Int $\mathrm{J}$ Colorectal Dis 2013;28(4):469-76.

[3] Bertelson NL, Kalkbrenner KA, Merchea A, et al. Colectomy for endoscopically unresectable polyps: how often is it cancer? Dis Colon Rectum 2012;55(11):1111-6.

[4] Jass JR. The large intestine in systemic pathology. Vol 3. Alimentary tract. $3^{\text {rd }}$ edn. Mirsun BC, General editor Symmer,s W. Stc. Churchill Livingstone, New York, 1987:365-77.

[5] Oshima CT, Iriya K, Forones NM. Ki-67 as a prognostic marker in colorectal cancer but not in gastric cancer. Neoplasma 2005;52(5):420-4.

[6] Quirke P, Risio M, Lambert R, et al. Quality assurance in pathology in colorectal cancer screening and diagnosis-European recommendations. Virchows Arch 2011;458(1):1-19.

[7] Nabi U, Nagi AH, Sami W. Ki-67 proliferating index and histological grade, type and stage of colorectal carcinoma. J Ayub Med Coll Abbottabad 2008;20(4):44-8.

[8] Khatibzadeh N, Ziaee SA, Rahbar N, et al. The indirect role of site distribution in high grade dysplasia in adenomatous colorectal polyps. J Cancer Res Ther 2005;1(4):204-7.

[9] Tony J, Harish K, Ramachandran TM, et al. Profile of colonic polyps in a southern Indian population. Indian J Gastroenterol 2007;26(3):127-9. 